\title{
Helium nanodroplets doped with copper and water ${ }^{\star}$
}

\author{
Stefan Raggl ${ }^{1}$, Norbert Gitzl ${ }^{1}$, Paul Martini ${ }^{1}$, Paul Scheier ${ }^{1, \text { a }}$, and Olof Echt ${ }^{1,2, b}$ \\ ${ }^{1}$ Institut für Ionenphysik und Angewandte Physik, Universität Innsbruck, Technikerstr. 25, 6020 Innsbruck, Austria \\ ${ }^{2}$ Physics Department, University of New Hampshire, Durham NH 03824, USA
}

Received 2 April 2018 / Received in final form 10 May 2018

Published online 12 July 2018

(C) The Author(s) 2018. This article is published with open access at Springerlink.com

\begin{abstract}
Copper nanoparticles are promising, low-cost candidates for the catalytic splitting of water and production of hydrogen gas. The present gas-phase study, based on the synthesis of copper-water complexes in ultracold helium nanodroplets followed by electron ionization, attempts to find evidence for dissociative water adsorption and $\mathrm{H}_{2}$ formation. Mass spectra show that $\mathrm{H}_{2} \mathrm{O}-\mathrm{Cu}$ complexes containing dozens of copper and water molecules can be formed in the helium droplets. However, ions that would signal the production and escape of $\mathrm{H}_{2}$, such as $\left(\mathrm{H}_{2} \mathrm{O}\right)_{n-2}(\mathrm{OH})_{2} \mathrm{Cu}_{m}{ }^{+}$or the isobaric $\left(\mathrm{H}_{2} \mathrm{O}\right)_{n-1} \mathrm{OCu}_{m}{ }^{+}$, could not be detected. We do observe an interesting anomaly though: While the abundance of stoichiometric $\left(\mathrm{H}_{2} \mathrm{O}\right)_{n} \mathrm{Cu}_{m}{ }^{+}$ions generally exceeds that of protonated or dehydrogenated ions, the trend is reversed for $\left(\mathrm{H}_{2} \mathrm{O}\right) \mathrm{OHCu}_{2}{ }^{+}$and $\left(\mathrm{H}_{2} \mathrm{O}\right)_{2} \mathrm{OHCu}_{2}{ }^{+}$; these ions are more abundant than $\left(\mathrm{H}_{2} \mathrm{O}\right)_{2} \mathrm{Cu}_{2}{ }^{+}$and $\left(\mathrm{H}_{2} \mathrm{O}\right)_{3} \mathrm{Cu}_{2}{ }^{+}$, respectively. Moreover, $\left(\mathrm{H}_{2} \mathrm{O}\right)_{2} \mathrm{OHCu}_{2}{ }^{+}$is much more abundant than other ions in the $\left(\mathrm{H}_{2} \mathrm{O}\right)_{n-1} \mathrm{OHCu}_{2}{ }^{+}$series. A byproduct of our experiment is the observation of enhanced stability of $\mathrm{He}_{6} \mathrm{Cu}^{+}, \mathrm{He}_{12} \mathrm{Cu}^{+}, \mathrm{He}_{24} \mathrm{Cu}^{+}$, and $\mathrm{He}_{2} \mathrm{Cu}_{2}{ }^{+}$.
\end{abstract}

\section{Introduction}

Copper nanoparticles dispersed in water or in the form of coatings have a range of promising uses, including lubrication, ink jet printing, as luminescent probes, exploiting their antimicrobial and antifungal activity, and in fuel cells [1-6]. Thermodynamic data predict that water splitting at monocrystalline copper surfaces does not produce significant amounts of molecular hydrogen but the evolution of hydrogen gas from oxygen-free water in contact with copper surfaces has been observed [7].

Theoretical studies of the reaction of water with surfaces of crystalline copper have been reported by Johansson et al. [8] and Lousada et al. [9]. At the lowdensity [110] surface, dissociation of adsorbed $\mathrm{H}_{2} \mathrm{O}$ is spontaneous; it has a lower activation energy than at the higher-density [100] or [111] surface. The activation energy decreases with increasing water coverage. The autocatalytic dissociation of water on the $\mathrm{Cu}[110]$ surface has, indeed, been identified by photoelectron spectroscopy at near-ambient conditions [10].

Johansson et al. have suggested that water oxidizes $\mathrm{Cu}[100]$ until the surface is saturated with hydroxyl groups, and that $\mathrm{H}_{2}$ forms by direct combination of hydrogen atoms at the surface [8]. Lousada et al. conclude that a monolayer of molecularly adsorbed $\mathrm{H}_{2} \mathrm{O}$ at $\mathrm{Cu}[110]$

${ }^{\star}$ Contribution to the Topical Issue "Atomic Cluster Collisions", edited by Alexey Verkhovtsev, Andrey V. Solov'yov, Germán Rojas-Lorenzo, and Jesús Rubayo Soneira.

${ }^{a}$ e-mail: paul.scheier@uibk.ac.at

b e-mail: olof .echt@unh.edu spontaneously converts to $\frac{1}{2}$ monolayer of $\mathrm{OH}$ plus $\frac{1}{2}$ monolayer of $\mathrm{H}_{2} \mathrm{O}$ accompanied by the release of hydrogen gas [9].

In industrial applications the surface of a copper catalyst is not crystalline. Some catalytic reactions may be promoted by atoms or small clusters of copper $[11,12]$. Huseyinova et al. have reported the synthesis of surfactant-free, nearly mono-disperse $\mathrm{Cu}_{5}$ clusters in water that are stable to UV irradiation, elevated temperature, and a wide range of $\mathrm{pH}$ [13]. Their catalytic activity has not yet been measured, but several theoretical studies of water dissociation on $\mathrm{Cu}_{7}$ have been reported [14-16]. $\mathrm{Cu}_{7}$ represents a prototypical cluster because most DFT-based calculations predict that the ground-state structures of copper clusters $\mathrm{Cu}_{m}$ are planar for $3 \leq m \leq 6$ while $\mathrm{Cu}_{7}$ forms a pentagonal bipyramid [17].

Based on a DFT approach, Chen et al. conclude that the main driving force for the adsorption of $\mathrm{H}_{2} \mathrm{O}$ at $\mathrm{Cu}_{7}$ is the overlap between the $p$-orbital of $\mathrm{O}$ occupied by the lone pair and the $3 d$ orbitals of $\mathrm{Cu}$ [14]. Dissociative adsorption of a single $\mathrm{H}_{2} \mathrm{O}$ to form $\mathrm{OH}$ and $\mathrm{H}$ is exothermic with a moderately high barrier. The reaction can be catalyzed by another $\mathrm{H}_{2} \mathrm{O}$ via hydrogen bonding. At high water coverage, the reaction becomes much more favorable both thermochemically and kinetically. Two $\mathrm{OH}$ species can react to form an $\mathrm{O}$ adatom plus $\mathrm{H}_{2} \mathrm{O}$.

A DFT study by Stenlid et al. focuses on the formation of molecular hydrogen upon reaction of $\mathrm{H}_{2} \mathrm{O}$ with $\mathrm{Cu}_{7}$, and the role of large water coverage [15]. The authors conclude that the reaction of an adsorbed $\mathrm{H}$ atom with $\mathrm{H}_{2} \mathrm{O}$ yielding $\mathrm{H}_{2}+\mathrm{OH}$ is much faster than the direct 
combination of two $\mathrm{H}$ atoms. Under atmospheric $\mathrm{H}_{2}$ pressure the thermodynamically most favored reaction is $\mathrm{Cu}_{7}+8 \mathrm{H}_{2} \mathrm{O} \rightarrow(\mathrm{OH})_{8} \mathrm{Cu}_{7}+4 \mathrm{H}_{2}$.

The reports discussed so far involve neutral complexes. Water splitting in ionic systems is of interest, too, because in the condensed phase metallic clusters may be charged [16]. Furthermore, the influence of the charge will likely decrease as the size of the copper cluster increases.

Several experimental studies of ionic copper-water complexes in the gas phase have been reported; most are restricted to atomic $\mathrm{Cu}^{+}$or $\mathrm{Cu}^{2+}$. Holland and Castleman have used high-pressure mass spectrometry to determine thermochemical properties of $\left(\mathrm{H}_{2} \mathrm{O}\right)_{n} \mathrm{Cu}^{+}$ for $n=3,4,5$ [18]. Michl and coworkers as well as Armentrout and coworkers measured dissociation energies $D_{n}$ (or sequential binding energies) of $\left(\mathrm{H}_{2} \mathrm{O}\right)_{n} \mathrm{Cu}^{+}$ for $1 \leq n \leq 4$ by collision-induced dissociation [19,20]. $\left(\mathrm{H}_{2} \mathrm{O}\right)_{2} \mathrm{Cu}^{+}$is remarkably stable; it's dissociation energy $(1.7 \mathrm{eV})$ exceeds that of $\left(\mathrm{H}_{2} \mathrm{O}\right) \mathrm{Cu}^{+}$by about $0.2 \mathrm{eV}$ [19]. Several theoretical studies have shown that $\mathrm{Cu}^{+}$is, indeed, two-fold coordinated; the oxygen atoms of the first two $\mathrm{H}_{2} \mathrm{O}$ bind to opposite sides of $\mathrm{Cu}^{+}$[21-25]. The interaction is nearly evenly divided among electrostatic, polarization, and charge transfer; the $\mathrm{Cu}$ Mulliken charge is only $+0.85 e$ [25]. Properties of $\left(\mathrm{H}_{2} \mathrm{O}\right)_{n} \mathrm{Cu}^{+}$have also been explored by vibrational spectroscopy [26-28]. $\left(\mathrm{H}_{2} \mathrm{O}\right)_{n} \mathrm{OHCu}^{+}$complexes have been characterized by vibrational spectroscopy and collision-induced dissociation [29-32] as well as theoretical modeling [31].

In contrast to these numerous studies of $\left(\mathrm{H}_{2} \mathrm{O}\right)_{n} \mathrm{Cu}^{+}$ and $\left(\mathrm{H}_{2} \mathrm{O}\right)_{n} \mathrm{OHCu}^{+}$, we are aware of only two gasphase studies that mention complexes containing more than one copper atom. Michl and coworkers observed $\left(\mathrm{H}_{2} \mathrm{O}\right)_{n} \mathrm{HCu}_{2}{ }^{+},\left(\mathrm{H}_{2} \mathrm{O}\right)_{n-1} \mathrm{OHCu}_{2}{ }^{+}$, and $\left(\mathrm{H}_{2} \mathrm{O}\right)_{n-1} \mathrm{OCu}_{2}{ }^{+}$ but no $\left(\mathrm{H}_{2} \mathrm{O}\right)_{n} \mathrm{Cu}_{2}{ }^{+}$upon fast-atom bombardment of frosted copper surfaces; unfortunately they did not quantify the yield of these ions nor the range of $n$ values [19] (Here the chemical formulas are written such that the subscript $n$ specifies the number of oxygen atoms; they do not necessarily convey structural information). Stace and coworkers used a pulsed-arc cluster source; they observed predominantly $\left(\mathrm{H}_{2} \mathrm{O}\right)_{n} \mathrm{HCu}_{2}{ }^{+}$ and $\left(\mathrm{H}_{2} \mathrm{O}\right)_{n} \mathrm{H}_{2} \mathrm{Cu}_{2}{ }^{+} \quad(n \leq 10), \quad\left(\mathrm{H}_{2} \mathrm{O}\right)_{n-1} \mathrm{OHCu}_{3}{ }^{+}$, and $\left(\mathrm{H}_{2} \mathrm{O}\right)_{n-1} \mathrm{OCu}_{3}{ }^{+}$[33]. Pure hydrated $\mathrm{Cu}_{2}{ }^{+}$and $\mathrm{Cu}_{3}{ }^{+}$was noticeably absent, with the exception of $\mathrm{H}_{2} \mathrm{OCu}_{3}{ }^{+}$.

In the present work we have synthesized neutral copper-water complexes by successively doping cold $(0.37 \mathrm{~K})$, superfluid helium nanodroplets with copper atoms and water molecules; the droplets are then ionized by electrons. The composition of the most prominent ions depends on the partial pressures in the pickup cell. We observe ions containing several copper atoms and several dozen water molecules. The stoichiometries of the most prominent ions are $\left(\mathrm{H}_{2} \mathrm{O}\right)_{n} \mathrm{Cu}_{m}{ }^{+}$, $\left(\mathrm{H}_{2} \mathrm{O}\right)_{n-1} \mathrm{OHCu}_{m}{ }^{+}$, and $\left(\mathrm{H}_{2} \mathrm{O}\right)_{n} \mathrm{HCu}_{m}{ }^{+}$. Surprisingly, $\left(\mathrm{H}_{2} \mathrm{O}\right)_{n} \mathrm{Cu}_{m}+$ ions which were essentially absent from previous work $[19,33]$ form the most abundant ion series, with just one exception: $\left(\mathrm{H}_{2} \mathrm{O}\right)_{2} \mathrm{OHCu}_{2}{ }^{+}$is more abundant than $\left(\mathrm{H}_{2} \mathrm{O}\right)_{3} \mathrm{Cu}_{2}{ }^{+}$. We have not been able to clearly identify $\left(\mathrm{H}_{2} \mathrm{O}\right)_{n-1} \mathrm{OCu}_{m}+$ which could indicate $\mathrm{H}_{2}$ formation, but the mass spectra are highly congested.

As a by-product, we have recorded mass spectra of helium droplets doped with copper but no water, leading to the formation of $\mathrm{He}_{n} \mathrm{Cu}_{m}{ }^{+}$. The $\mathrm{He}_{n} \mathrm{Cu}^{+}$series features local maxima at $n=6,12$ and 24. Maxima at $n=6$ and 12 have previously been observed for $\mathrm{Ar}_{n} \mathrm{Cu}^{+}$ and $\mathrm{Ne}_{n} \mathrm{Cu}^{+}$, respectively, and rationalized by DFT calculations [34]. The significance of those observations for our results will be discussed.

\section{Experiment}

Helium nanodroplets were produced by expanding helium (Linde, purity $99.9999 \%$ ) at a stagnation pressure of 25 bar through a $5 \mu \mathrm{m}$ nozzle, cooled by a closed-cycle cryostat to between 9 and $10 \mathrm{~K}$, into vacuum. Droplets formed at these conditions contain roughly $10^{6}$ atoms. The exact temperatures and estimated [35] average numbers of helium atoms in the droplets will be specified in the Result section.

The expanding beam was skimmed by a $0.8 \mathrm{~mm}$ conical skimmer located $8 \mathrm{~mm}$ downstream from the nozzle and traversed an $8 \mathrm{~cm}$ long, differentially pumped pick-up cell filled with copper vapor produced in a resistively heated oven. The temperature of the copper oven could not be measured directly; it was adjusted in order to obtain the optimal conditions for formation of either $\mathrm{He}_{n} \mathrm{Cu}_{m}{ }^{+}$or $\left(\mathrm{H}_{2} \mathrm{O}\right)_{n} \mathrm{Cu}_{m}{ }^{+}$cluster ions. Water vapor was introduced into a second differentially pumped pickup chamber from an external water reservoir.

The beam of doped helium droplets was collimated and crossed by an electron beam with a nominal energy of 70-80 eV. Cations were accelerated into the extraction region of a reflectron time-of-flight mass spectrometer (Tofwerk AG, model HTOF) with an effective mass resolution $m / \Delta m=3000$ ( $\Delta m=$ full-width-at-halfmaximum). The base pressure in the mass spectrometer was $10^{-5} \mathrm{~Pa}$. Ions were extracted at $90^{\circ}$ into the fieldfree region of the spectrometer by a pulsed voltage. At the end of the field-free region they entered a two-stage reflectron which reflected them towards a microchannel plate detector operated in single ion counting mode. Further experimental details have been provided elsewhere [36].

Mass spectra were evaluated by means of a customdesigned software [37]. The abundance of ions is derived from the mass spectra by a matrix method. The routine includes automatic fitting of a custom peak shape to the mass peaks and subtraction of background by fitting a spline to the background level of the raw data. Hydrogen and helium are very nearly monoisotopic (the natural abundance of deuterium is $0.0115 \%$; that of ${ }^{3} \mathrm{He}$ is $0.000137 \%$ ) but copper has two naturally occurring isotopes, ${ }^{63} \mathrm{Cu}$ (mass $62.9296 \mathrm{u}$, natural abundance $69.17 \%$ ) and ${ }^{65} \mathrm{Cu}(64.9278 \mathrm{u}, 30.83 \%)$.

\section{Experimental results}

Figure 1a displays a mass spectrum of helium nanodroplets doped with copper but no water, ionized 


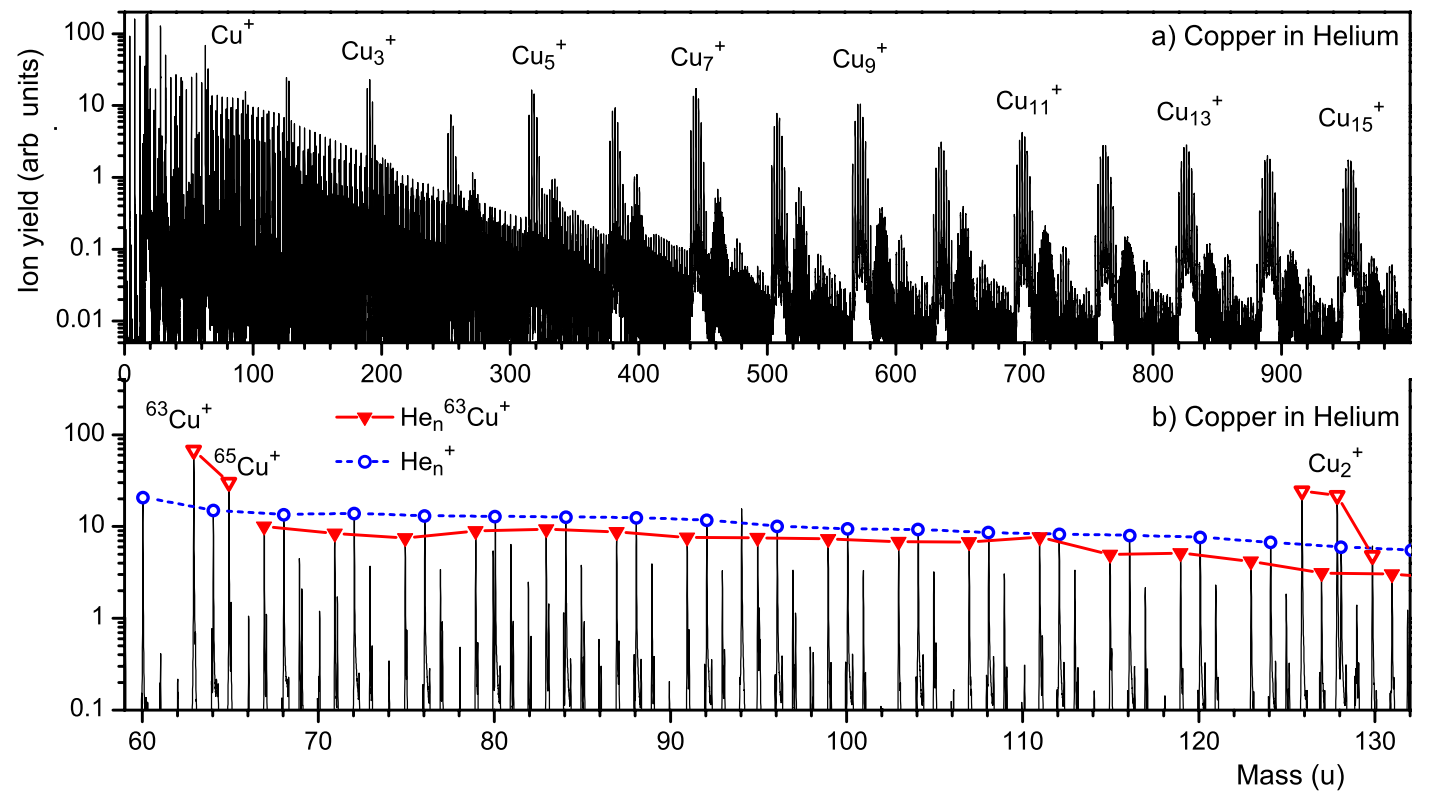

Fig. 1. Panel (a) shows a mass spectrum of helium droplets (estimated average size $5 \times 10^{6}$ atoms) doped with copper but no water. The most prominent series of mass peaks are due to $\mathrm{He}_{n}{ }^{+}$and $\mathrm{Cu}_{m}{ }^{+}$. Local variations in the ion yield of $\mathrm{Cu}_{m}{ }^{+}$ reflect variations in cluster stability due to electronic shell effects. Panel (b) displays a section of the spectrum; mass peaks due to $\mathrm{He}_{n}^{+}$(open circles) and $\mathrm{He}_{n}{ }^{63} \mathrm{Cu}_{m}{ }^{+}$(full triangles) are flagged. Open triangles mark the two isotopes of $\mathrm{Cu}^{+}$and the three isotopologues of $\mathrm{Cu}_{2}{ }^{+}$.

at an electron energy of $71 \mathrm{eV}$. Helium was expanded at 25 bar through a $5 \mu \mathrm{m}$ nozzle cooled to $9.25 \mathrm{~K}$. At these conditions, the estimated average number of helium atoms in a droplet is $5 \times 10^{6}$ helium atoms [35].

The most prominent mass peaks in Figure 1a are due to $\mathrm{Cu}_{m}{ }^{+}, m \leq 15$. Complexes of $\mathrm{Cu}_{m}{ }^{+}$with a water molecule (due to a water contamination) become apparent for $m \geq 3$; for $m \geq 7$ complexes with two water molecules appear as well. Another minor contamination is assigned to $\mathrm{PH}^{+}$(mass $31.982 \mathrm{u}$ ); it appears when the copper oven is heated. The mass peak of $\mathrm{PH}^{+}$is distinct from that of $\mathrm{O}_{2}{ }^{+}(31.990 \mathrm{u})$ but $\mathrm{PHCu}_{m}{ }^{+}$and $\mathrm{O}_{2} \mathrm{Cu}_{m}{ }^{+}$cannot be distinguished for $m \geq 1$.

Figure $1 \mathrm{~b}$ zooms into the mass region between $\mathrm{Cu}^{+}$ and $\mathrm{Cu}_{2}{ }^{+}$. The two naturally occurring isotopes of copper $\left({ }^{63} \mathrm{Cu}\right.$ and $\left.{ }^{65} \mathrm{Cu}\right)$ and the three isotopologues of $\mathrm{Cu}_{2}$ are marked by open triangles. Solid triangles connected by a solid line mark mass peaks due to $\mathrm{He}_{n}{ }^{63} \mathrm{Cu}^{+}$; they are nearly as intense as pure $\mathrm{He}_{n}{ }^{+}$ions (open dots connected by a dotted line).

Figure 2 displays the ion abundance of $\mathrm{He}_{n} \mathrm{Cu}^{+}$and $\mathrm{He}_{n} \mathrm{Cu}_{2}{ }^{+}$deduced from the mass spectrum in Figure 1 with a custom-designed software [37]. Uncertainties are reported by the software; a few statistically significant anomalies are marked. Some error bars are very large as a result of mass spectral coincidence with potential contaminants. For example, $\mathrm{He}_{4}{ }^{63} \mathrm{Cu}^{+}$and $\mathrm{He}_{4}{ }^{65} \mathrm{Cu}^{+}$cannot be distinguished from $\mathrm{O}^{63} \mathrm{Cu}^{+}$and $\mathrm{H}_{2} \mathrm{O}^{63} \mathrm{Cu}^{+}$, respectively (the relative mass differences are $\Delta m / m \leq 2 \times 10^{-4}$ ).

A mass spectrum of helium droplets doped with copper and water is presented in Figure 3. Data were recorded with a helium stagnation pressure of 25 bar, nozzle temperature $9.65 \mathrm{~K}$, estimated droplet size $5 \times 10^{5}$ atoms,

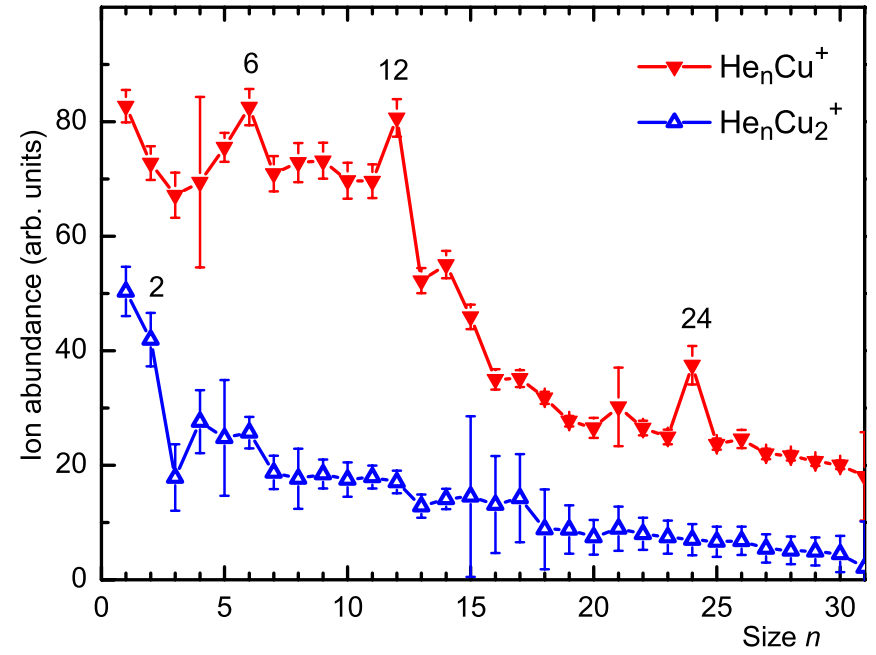

Fig. 2. The ion abundance of $\mathrm{He}_{n} \mathrm{Cu}^{+}$and $\mathrm{He}_{n} \mathrm{Cu}_{2}{ }^{+}$deduced from the mass spectrum displayed in Figure 1.

electron energy $80 \mathrm{eV}$. The total pressure (mostly water) in the pickup cell was $1 \times 10^{-5}$ mbar. The temperature of the copper oven was about the same as used to record the spectrum in Figure 1. The most prominent mass peaks in Figure 3 are due to $\mathrm{He}_{n}{ }^{+}$and, above about $150 \mathrm{u}$, $\left(\mathrm{H}_{2} \mathrm{O}\right)_{n} \mathrm{H}^{+}$(for the sake of consistency, we write all chemical formulas such that the subscript $n$ specifies the number of oxygen atoms in a complex; they are not meant to convey structural information).

Figure 4 zooms into a section of the spectrum. Mass peaks due to $\left(\mathrm{H}_{2} \mathrm{O}\right)_{n}{ }^{63} \mathrm{Cu}^{+}$are marked by solid triangles, 


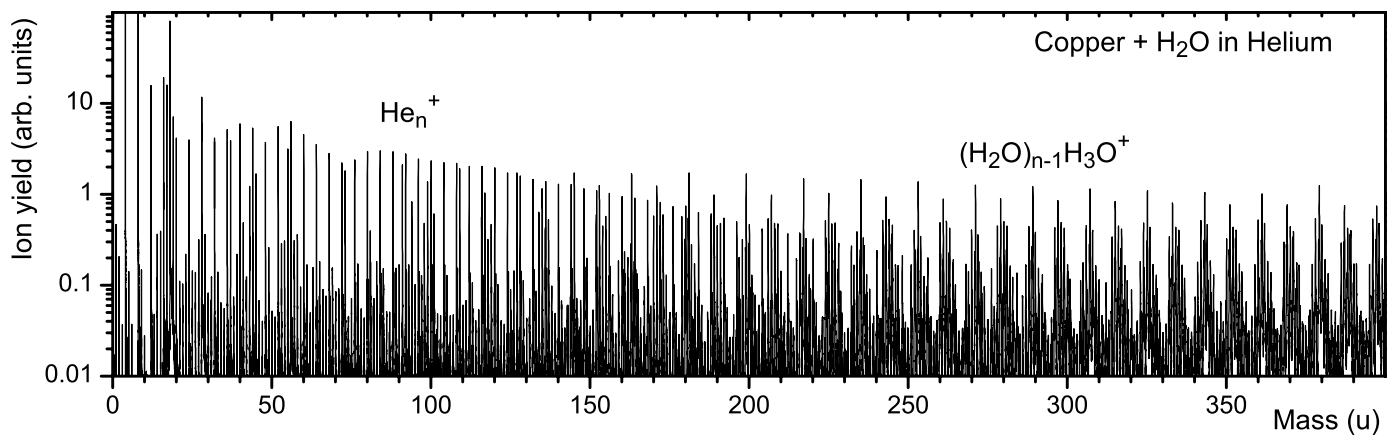

Fig. 3. Mass spectrum of helium droplets (estimated average size $5 \times 10^{5}$ atoms) doped with copper and water. The most prominent ion series below $150 \mathrm{u}$ is due to $\mathrm{He}_{n}{ }^{+}$; at higher masses pure protonated water clusters dominate.

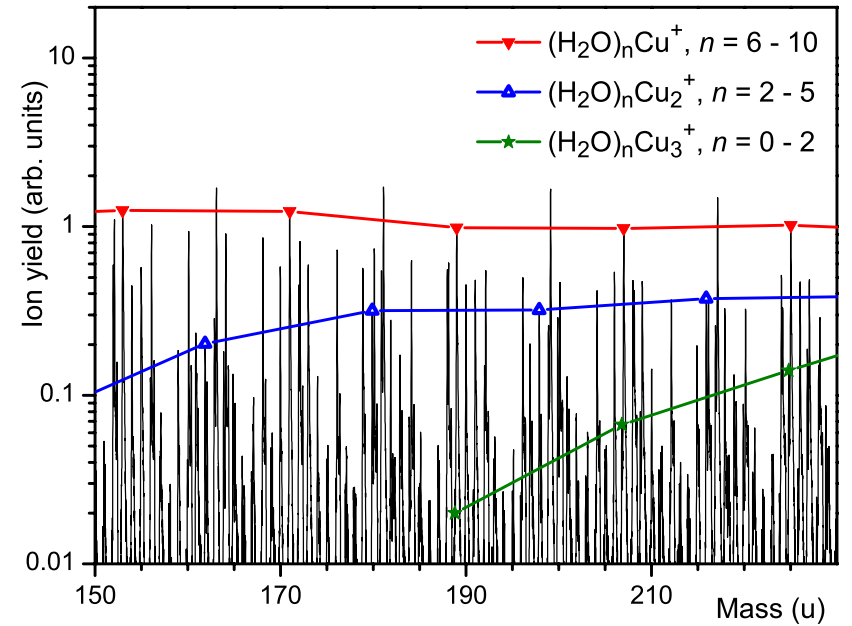

Fig. 4. A section of the spectrum displayed in Figure 3. Mass peaks due to $\left(\mathrm{H}_{2} \mathrm{O}\right)_{n}{ }^{63} \mathrm{Cu}^{+},\left(\mathrm{H}_{2} \mathrm{O}\right)_{n}{ }^{63} \mathrm{Cu}_{2}{ }^{+}$, and $\left(\mathrm{H}_{2} \mathrm{O}\right)_{n}{ }^{63} \mathrm{Cu}_{3}{ }^{+}$are marked. The most prominent mass peaks (not marked) are due to protonated water clusters.

peaks due to $\left(\mathrm{H}_{2} \mathrm{O}\right)_{n}{ }^{63} \mathrm{Cu}_{2}{ }^{+}$by open triangles, peaks due to $\left(\mathrm{H}_{2} \mathrm{O}\right)_{n}{ }^{63} \mathrm{Cu}_{3}+$ by stars.

The ion abundance of $\left(\mathrm{H}_{2} \mathrm{O}\right)_{n} \mathrm{Cu}_{m}{ }^{+}$extracted from this spectrum for $1 \leq m \leq 7$ is displayed in Figure 5 . For clarity, data for $m=4$ and 6 have been omitted; they smoothly interpolate between distributions of their next smaller and larger sibblings. Strong, statistically significant local maxima in the distributions at $\left(\mathrm{H}_{2} \mathrm{O}\right)_{2} \mathrm{Cu}^{+}$and $\left(\mathrm{H}_{2} \mathrm{O}\right)_{3} \mathrm{Cu}_{3}{ }^{+}$and an abrupt drop beyond $\left(\mathrm{H}_{2} \mathrm{O}\right)_{6} \mathrm{Cu}^{+}$are marked.

Figure 6 compiles the ion abundances of $\left(\mathrm{H}_{2} \mathrm{O}\right)_{n} \mathrm{Cu}_{m}{ }^{+}$, $\left(\mathrm{H}_{2} \mathrm{O}\right)_{n} \mathrm{HCu}_{m}{ }^{+}$, and $\left(\mathrm{H}_{2} \mathrm{O}\right)_{n-1} \mathrm{OHCu}_{m}{ }^{+}$cluster ions for $m=1,2,3$ (panels (a), (b), and (c), respectively). Stoichiometric $\left(\mathrm{H}_{2} \mathrm{O}\right)_{n} \mathrm{Cu}_{m}{ }^{+}$ions are nearly always more abundant than the protonated or dehydrogenated ions with the same $(\mathrm{m}, \mathrm{n})$ values, but $\left(\mathrm{H}_{2} \mathrm{O}\right) \mathrm{OHCu}_{2}{ }^{+}$and $\left(\mathrm{H}_{2} \mathrm{O}\right)_{2} \mathrm{OHCu}_{2}{ }^{+}$are more abundant than $\left(\mathrm{H}_{2} \mathrm{O}\right)_{2} \mathrm{Cu}_{2}{ }^{+}$and $\left(\mathrm{H}_{2} \mathrm{O}\right)_{3} \mathrm{Cu}_{2}{ }^{+}$, respectively. Furthermore, $\left(\mathrm{H}_{2} \mathrm{O}\right)_{2} \mathrm{OHCu}_{2}{ }^{+}$(i.e. $n=3$ ) forms a pronounced local maximum in the series of dehydrogenated ions. The local anomalies marked in panels (a) $\left(\left(\mathrm{H}_{2} \mathrm{O}\right)_{2} \mathrm{Cu}^{+}\right.$and $\left.\left.\left(\mathrm{H}_{2} \mathrm{O}\right)_{6} \mathrm{Cu}^{+}\right)\right)$and $(\mathrm{c})\left(\left(\mathrm{H}_{2} \mathrm{O}\right)_{3} \mathrm{Cu}_{3}{ }^{+}\right)$ were already mentioned in the context of Figure 5.

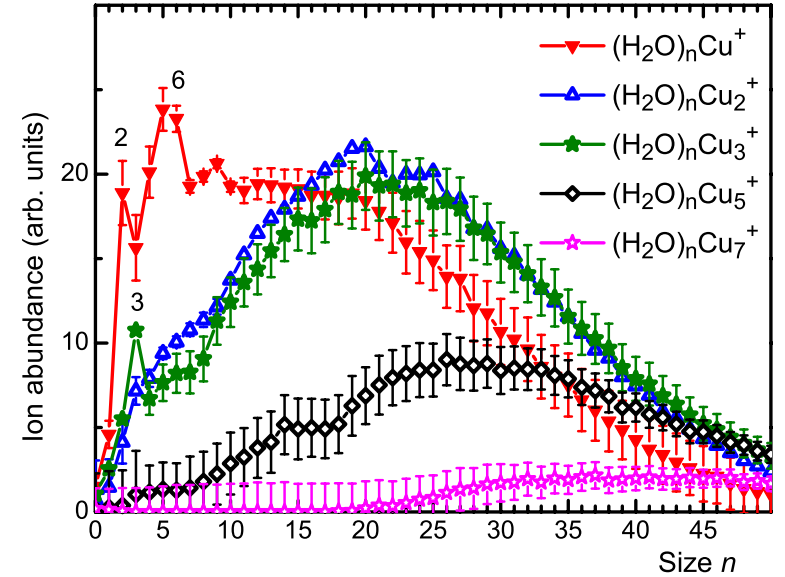

Fig. 5. The ion abundance of $\left(\mathrm{H}_{2} \mathrm{O}\right)_{n} \mathrm{Cu}_{m}{ }^{+}$versus $n$ for $m=1,2,3,5,7$, extracted from the mass spectrum displayed in Figure 3.

\section{Discussion}

\subsection{Copper-water complexes}

The main motivation for the present work is the identification of ions that might signal the splitting of water on the surface of copper cluster ions. Several theoretical studies suggest that hydration of $\mathrm{Cu}_{7}$ may lead to the evolution of molecular $\mathrm{H}_{2}$ [14-16]. Water splitting can be catalyzed by another $\mathrm{H}_{2} \mathrm{O}$ via hydrogen bonding. Water coverage beyond the first monolayer favors the reaction, thermochemically as well as kinetically [16].

These studies pertain to neutral clusters containing seven atoms $\left(\mathrm{Cu}_{7}\right.$ is commonly chosen because it is the smallest three-dimensional cluster, but the reaction energetics and kinetics may be similar for other small clusters [14]). In our experiment, neutral water-copper complexes are synthesized in superfluid helium nanodroplet by successive capture of $\mathrm{H}_{2} \mathrm{O}$ and $\mathrm{Cu}$, in random order. This is a statistical process which leads to a broad distribution in the size distribution of $\left(\mathrm{H}_{2} \mathrm{O}\right)_{x} \mathrm{Cu}_{y}$, amplified by the considerable size range of the helium nanodroplets. The mass spectra show that $x$ may be as large as $\approx 50$, and $y$ may exceed $\approx 20$. Presumably there is no lower limit to the values of $x$ and $y$. 


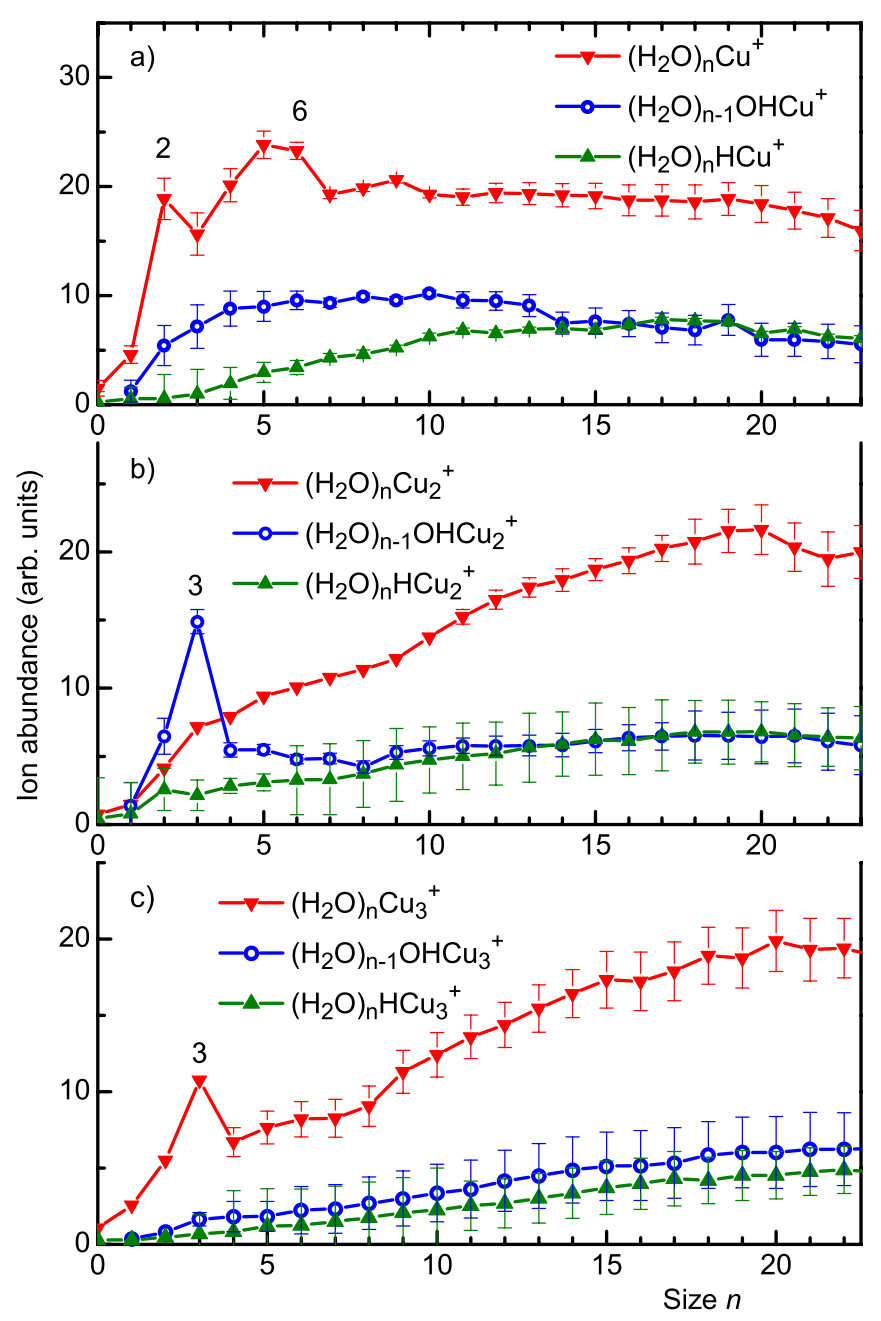

Fig. 6. The ion abundance of $\left(\mathrm{H}_{2} \mathrm{O}\right)_{n} \mathrm{Cu}_{m}{ }^{+}$together with that of dehydrogenated and protonated ions, for $m=1,2,3$ (panels (a), (b), and (c), respectively). Values of $n$ at which strong local anomalies occur are marked.

Water splitting is unlikely to occur during synthesis of $\left(\mathrm{H}_{2} \mathrm{O}\right)_{x} \mathrm{Cu}_{y}$ in a helium droplet because the droplet temperature is only $0.37 \mathrm{~K}$; the energy released upon aggregation is rapidly removed by evaporation of helium atoms (which costs about $0.6 \mathrm{meV}$ per atom). However, ionization of the dopant is an indirect process which starts with the formation of $\mathrm{He}^{+}$and resonant hole hopping, or of electronically excited, highly mobile $\mathrm{He}^{*-}$ [38]. Formation of $\mathrm{He}^{+}$requires about $24.6 \mathrm{eV}$ while the ionization energy of $\mathrm{Cu}$ is $7.73 \mathrm{eV}$; the difference will be released upon charge transfer between $\mathrm{He}^{+}$and $\mathrm{Cu}$. The excess energy would be a few eV smaller if ionization involves $\mathrm{He}^{*-} .{ }^{1}$ On the other hand, the excess energy would be a few eV larger for large copper clusters whose ionization energies converge towards the copper work function $(\approx 5 \mathrm{eV})$. Thus an excess energy of $17 \mathrm{eV}$, give or take a few $\mathrm{eV}$, will be released upon ionization of the dopant.

\footnotetext{
${ }^{1}$ Furthermore, the emitted electrons could possibly carry away a large fraction of the excess energy.
}

Electron ionization mass spectra of clusters embedded in helium nanodroplets do, in fact, indicate extensive intra- and intermolecular fragmentation. Often the spectra are very similar to mass spectra recorded by direct electron ionization of bare clusters at commonly used $(70 \mathrm{eV})$ energies. For example, electron ionization of water clusters embedded in helium as well as electron ionization of bare water clusters result in predominantly protonated water cluster ions, $\left(\mathrm{H}_{2} \mathrm{O}\right)_{n} \mathrm{H}^{+}$, and an abrupt drop in the ion abundance at $n=21[39,40]$.

Furthermore, the mass spectrum in Figure 1 provides direct evidence for ionization-induced dissociation. Although the size distribution of neutral clusters is smooth because of the statistical nature of the capture process, the measured abundance distribution of $\mathrm{Cu}_{m}{ }^{+}$ closely tracks the size dependence of their dissociation energies, with the electronically closed-shell $\mathrm{Cu}_{3}{ }^{+}$and $\mathrm{Cu}_{9}{ }^{+}$being much more stable than $\mathrm{Cu}_{4}{ }^{+}$and $\mathrm{Cu}_{10}{ }^{+}$, respectively [41]. The evaporative model explains why local anomalies in cluster ion abundance distributions reflect anomalies in their relative dissociation energies, provided each cluster ion has lost at least one atom before the distribution is being measured $[42,43]$. The dissociation energies of $\mathrm{Cu}_{3}{ }^{+}$and $\mathrm{Cu}_{9}{ }^{+}$are 2.83 and $3.66 \mathrm{eV}$ [41] proving that ample energy becomes available when copper clusters embedded in helium are ionized by electron impact.

Splitting of water adsorbed on copper cluster ions followed by generation and escape of $\mathrm{H}_{2}$ would be described by the reaction

$$
\left(\mathrm{H}_{2} \mathrm{O}\right)_{\mathrm{n}} \mathrm{Cu}_{\mathrm{m}}^{+} \rightarrow\left(\mathrm{H}_{2} \mathrm{O}\right)_{\mathrm{n}-2}(\mathrm{OH})_{2} \mathrm{Cu}_{\mathrm{m}}{ }^{+}+\mathrm{H}_{2},
$$

which could possibly be followed by the reaction

$$
\left(\mathrm{H}_{2} \mathrm{O}\right)_{\mathrm{n}-2}(\mathrm{OH})_{2} \mathrm{Cu}_{\mathrm{m}}^{+} \rightarrow\left(\mathrm{H}_{2} \mathrm{O}\right)_{\mathrm{n}-1} \mathrm{OCu}_{\mathrm{m}}{ }^{+} .
$$

A mass spectrum cannot distinguish between the reactant and product of reaction (2); the ion would commonly be identified as $\left(\mathrm{H}_{2} \mathrm{O}\right)_{n-1} \mathrm{OCu}_{m}{ }^{+}$. An even better indication of $\mathrm{H}_{2}$ production would be the reaction

$$
\begin{aligned}
\left(\mathrm{H}_{2} \mathrm{O}\right)_{\mathrm{n}} \mathrm{Cu}_{\mathrm{m}}^{+} & \rightarrow\left(\mathrm{H}_{2} \mathrm{O}\right)_{\mathrm{n}-4}(\mathrm{OH})_{4} \mathrm{Cu}_{\mathrm{m}}^{+}+2 \mathrm{H}_{2} \\
& \rightarrow\left(\mathrm{H}_{2} \mathrm{O}\right)_{\mathrm{n}-2} \mathrm{O}_{2} \mathrm{Cu}_{\mathrm{m}}{ }^{+}+2 \mathrm{H}_{2}
\end{aligned}
$$

Based on a DFT study of hydrated $\mathrm{Cu}_{7}$, Stenlid et al. concluded that as many as $4 \mathrm{H}_{2}$ might be generated, which would result in $\left(\mathrm{H}_{2} \mathrm{O}\right)_{n-8}(\mathrm{OH})_{8} \mathrm{Cu}_{7}$ or the isobaric $\left(\mathrm{H}_{2} \mathrm{O}\right)_{n-4}\left(\mathrm{O}_{2}\right)_{2} \mathrm{Cu}_{7}[16]$.

The theoretical studies of water dissociation on $\mathrm{Cu}_{7}$ focus on neutral copper clusters [14-16] but Stenlid et al. [16] briefly mention $\mathrm{Cu}_{7}{ }^{-}$and $\mathrm{Cu}_{7}{ }^{+}$as well. They point out that $\mathrm{Cu}_{7}+$ binds water more strongly, accommodates more water in the first solvation shell, and the $\mathrm{Cu}-\mathrm{Cu}$ distances in the equatorial plane are increased relative to neutral $\mathrm{Cu}_{7}$. It is not clear though to what degree the catalytic activities of $\mathrm{Cu}_{7}{ }^{+}$and $\mathrm{Cu}_{7}$ would differ.

We have searched for evidence of these types of water splitting reactions in our mass spectra, to no 
avail. Unfortunately the sensitivity to the detection of $\left(\mathrm{H}_{2} \mathrm{O}\right)_{n-x} \mathrm{O}_{x} \mathrm{Cu}_{m}{ }^{+}, x \geq 1$ is hampered by two factors. First, these types of ions cannot be positively identified for even-numbered $x$ in the mass range of interest $(\geq 63+32 \mathrm{u})$ because the mass of ions containing $\mathrm{O}_{2}$ becomes indistinguishable from the mass of ions containing the contaminant $\mathrm{PH}$. Second, the two naturally occuring isotopes of copper $\left({ }^{63} \mathrm{Cu}\right.$ and ${ }^{65} \mathrm{Cu}$, abundance $69.83 \%$ and $30.17 \%$, respectively) produce highly congested spectra. The isotopologues are easily resolved up to, at least, $\mathrm{Cu}_{15}{ }^{+}$(see the spectrum in Fig. 1a), but $\mathrm{O}^{65} \mathrm{Cu}^{+}$and $\mathrm{H}_{2} \mathrm{O}^{63} \mathrm{Cu}^{+}$differ by only $0.018 \mathrm{u}$. The mass resolution of our instrument, $m / \Delta m \approx 3000$, is not quite sufficient to resolve these two ions; resolving them in complexes containing more than one copper atom would be a hopeless task. Experiments with isotopically enriched ${ }^{63} \mathrm{Cu}$ would alleviate this problem.

Theoretical studies pertain to neutral copper clusters containing 7 atoms while our work pertains to cationic clusters. Furthermore, the mass spectral resolution and the occurrence of isotopologues limits the information that we can deduce for ions containing more than a few copper atoms. Carnegie et al. have performed infrared photodissociation spectroscopy of argon-tagged $\mathrm{H}_{2} \mathrm{OCu}^{+}$in the $\mathrm{O}-\mathrm{H}$ stretching region [28]. Iino et al. have used a similar approach to study argon-tagged $\left(\mathrm{H}_{2} \mathrm{O}\right)_{n} \mathrm{Cu}^{+}, n \leq 4$, and untagged $\left(\mathrm{H}_{2} \mathrm{O}\right)_{n} \mathrm{Cu}^{+}, n \leq 7$ [27]. Their work provides no evidence for water splitting.

The catalytic activity of $\mathrm{Cu}_{m}{ }^{+}$may be quite sensitive to its geometric and electronic structure, hence its size. In this context, the flagged feature in Figure $6 \mathrm{~b}$ is noteworthy. It shows a greatly enhanced yield of dehydrogenated ions for just two species, $\left(\mathrm{H}_{2} \mathrm{O}\right) \mathrm{OHCu}_{2}{ }^{+}$and $\left(\mathrm{H}_{2} \mathrm{O}\right)_{2} \mathrm{OHCu}_{2}{ }^{+}$. This suggests dissociative adsorption of $\mathrm{H}_{2} \mathrm{O}$ on $\mathrm{Cu}_{2}{ }^{+}$which would be a prerequisite for $\mathrm{H}_{2}$ formation. Theoretical work is needed to elucidate the origin of this feature. Dehydrogenated hydrated copper ions have been characterized by collision-induced dissociation [32] and vibrational spectroscopy [29-31] but we are not aware of related work on ions containing two or more copper atoms.

The results presented in Figure 6 are markedly different from those reported earlier [19-33]. Michl and coworkers applied secondary-ion mass spectrometry of copper covered with a frozen water film [19]. The copper monomer formed a series of hydrated ions $\left(\mathrm{H}_{2} \mathrm{O}\right)_{n} \mathrm{Cu}^{+}$but no dehydrogenated ions $\left(\mathrm{H}_{2} \mathrm{O}\right)_{n-1} \mathrm{OHCu}^{+}$. The copper dimer formed the protonated series, the dehydrogenated series, and the doubly dehydrogenated series $\left(\mathrm{H}_{2} \mathrm{O}\right)_{n-1} \mathrm{OCu}_{2}{ }^{+}$, but no $\left(\mathrm{H}_{2} \mathrm{O}\right)_{n} \mathrm{Cu}_{2}{ }^{+}$.

Stace and coworkers formed small copper cluster ions in an arc source; the ions were swept out by a helium carrier gas seeded with water vapor [33]. They detected only one complex containing a single copper atom, $\mathrm{HCu}^{+}$. The hydrated copper dimer appeared in two forms, $\left(\mathrm{H}_{2} \mathrm{O}\right)_{n-1} \mathrm{HCu}_{2}{ }^{+}$and $\left(\mathrm{H}_{2} \mathrm{O}\right)_{n-1} \mathrm{H}_{2} \mathrm{Cu}_{2}{ }^{+}$. The hydrated copper trimer appeared in the protonated, dehydrogenated, and doubly dehydrogenated form but no $\left(\mathrm{H}_{2} \mathrm{O}\right)_{n} \mathrm{Cu}_{3}{ }^{+}$was observed. Thus, while we find that $\left(\mathrm{H}_{2} \mathrm{O}\right)_{n} \mathrm{Cu}_{m}{ }^{+}$is (with the exception of $m=2, n=2$ and 3) the most intense ion series, that series was not observed at all in previous work (with the exception of $\left(\mathrm{H}_{2} \mathrm{O}\right)_{n} \mathrm{Cu}^{+}$[19]). Our tentative conjecture is that the very large excess energies that are available when ions are sputtered, or formed in a plasma, are responsible for the striking differences.

Finally we address the features marked in Figures $6 \mathrm{a}$ and $6 \mathrm{c}$. The dissociation energy of $\left(\mathrm{H}_{2} \mathrm{O}\right)_{2} \mathrm{Cu}^{+}$ is known to be about twice that of $\left(\mathrm{H}_{2} \mathrm{O}\right)_{3} \mathrm{Cu}^{+}$; it is even higher than that of $\left(\mathrm{H}_{2} \mathrm{O}\right) \mathrm{Cu}^{+}[18-20]$. This rather unusual feature has been traced to the peculiar structure of $\left(\mathrm{H}_{2} \mathrm{O}\right)_{2} \mathrm{Cu}^{+}$whose lowest-energy structure has the $\mathrm{H}_{2} \mathrm{O}$ molecules adsorbed on opposite sides of the $\mathrm{Cu}^{+}$ ion with the $\mathrm{O}$ atoms facing $\mathrm{Cu}^{+}$. Most theoretical studies agree that $\mathrm{Cu}^{+}$in $\left(\mathrm{H}_{2} \mathrm{O}\right)_{3} \mathrm{Cu}^{+}$and $\left(\mathrm{H}_{2} \mathrm{O}\right)_{4} \mathrm{Cu}^{+}$is two-fold coordinated, but the increase to three- or even four-fold coordination in ions containing as many $10 \mathrm{H}_{2} \mathrm{O}$ is less clear [21-25].

The local maximum in the abundance of $\left(\mathrm{H}_{2} \mathrm{O}\right)_{n} \mathrm{Cu}^{+}$ at $n=2$ (see Fig. 5) signals its high stability. We also see an abrupt drop of the abundance at $\left(\mathrm{H}_{2} \mathrm{O}\right)_{6} \mathrm{Cu}^{+}$which suggests a sudden decrease in the dissociation energy. The only theoretical study of ions in this size range [25] reported relative energies of structural isomers relative to the ground state structure; dissociation energies of $\left(\mathrm{H}_{2} \mathrm{O}\right)_{n} \mathrm{Cu}^{+}$ions in their ground state were not reported. However, it was noted that the coordination of $\mathrm{Cu}^{+}$ increased from two or three for $n=5,6$ to three or four for $n \geq 7$. It is tempting to conjecture that this change in coordination is accompanied by a weakening in binding.

A pronounced local maximum occurs in the abundance distribution of the $\left(\mathrm{H}_{2} \mathrm{O}\right)_{n} \mathrm{Cu}_{3}{ }^{+}$series at $n=3$. We are not aware of any studies of water adsorption on the copper trimer (nor trimers of other noble metals); theoretical work is needed to elucidate the origin of the apparent enhanced stability of $\left(\mathrm{H}_{2} \mathrm{O}\right)_{3} \mathrm{Cu}_{3}{ }^{+}$.

\subsection{Copper-helium complexes}

Figure 2 displays the abundance distributions of $\mathrm{He}_{n} \mathrm{Cu}^{+}$and $\mathrm{He}_{n} \mathrm{Cu}_{2}{ }^{+}$. Noteworthy are local maxima at $n=6,12$, and 24 in the $\mathrm{He}_{n} \mathrm{Cu}^{+}$series and an abrupt drop at $\mathrm{He}_{2} \mathrm{Cu}_{2}{ }^{+}$; the features suggest enhanced stability of these ions. The high abundance of $\mathrm{He}_{12} \mathrm{Cu}^{+}$might indicate icosahedral arrangement of the ligands, a structure observed for some other systems with non-directional bonding such as $\mathrm{He}_{n} \mathrm{~K}^{+}$[44], $\mathrm{He}_{n} \mathrm{Ar}^{+}$[45], $\mathrm{He}_{n} \mathrm{Ag}^{+}$[46], and $\mathrm{He}_{n} \mathrm{Au}^{+}$[47]. Another factor in the appearance of icosahedral structure is that the size of the ion, i.e. the ion-ligand bond length, has to be about right for the size of the ligands, i.e. the ligand-ligand bond length. For $\mathrm{He}_{n} \mathrm{Ar}^{+}$the match is near-perfect, resulting in a highly ordered system with three distinct solvation shells of $I_{h}$ symmetry [48].

For hard-sphere models, icosahedral packing is preferred if $\sigma^{*}$, the ratio of the ion-ligand and ligand-ligand lengths, lies between 0.82 and 0.95 [49]. Ab initio-calculations of the potential energy curves of $\mathrm{He}-\mathrm{Cu}^{+}$result in bond lengths $\left(R_{e}\right)$ of 1.93 or $1.95 \AA[50,51]$. The $\mathrm{He}-\mathrm{He}$ bond length depends very much on the environment because of the large zero point energy. If one uses the helium bulk density for an estimate (which gives results in 
reasonable agreement with dimer bond lengths for the heavier noble gases) one obtains $R_{e} \approx 2.52 \AA$ for $\mathrm{He}-\mathrm{He}$, and $\sigma^{*} \approx 0.77$. This value is midway between the range for which icosahedral packing would be favorable, and the range $0.61 \leq \sigma^{*} \leq 0.71$ for which octahedral packing would be favorable [49]. Thus the first two maxima in the abundance distribution in Figure 2, at $n=6$ and 12, are not inconsistent with expectations based on hard-sphere packing models.

The only realistic theoretical study (at the coupled cluster single double triple level) of the stability of $\mathrm{He}_{n} \mathrm{Cu}^{+}$ containing more than one helium atom was reported by $\mathrm{Li}$ et al. [52]; it extends to $n \leq 3$. The authors concluded that $\mathrm{He}_{2} \mathrm{Cu}^{+}$is linear with $D_{\infty}$ symmetry, and $\mathrm{He}_{3} \mathrm{Cu}^{+}$is planar with $D_{3 h}$ symmetry. These features are not consistent with the assumption of non-directional bonding.

Another study worth mentioning is by Froudakis et al. [34]. The authors reported mass spectra of $\mathrm{Ne}_{n} \mathrm{Cu}^{+}$and $\mathrm{Ar}_{n} \mathrm{Cu}^{+}$. The abundance distribution of $\mathrm{Ne}_{n} \mathrm{Cu}^{+}$suggested enhanced stability at $n=4$ and 12; DFT calculations confirmed this conjecture. The ground state structure of $\mathrm{Ne}_{12} \mathrm{Cu}^{+}$turned out to be icosahedral even though for $\mathrm{Ne}-\mathrm{Cu}^{+}$the value of $\sigma^{*}$ is only $\approx 0.66$, within the range where hard-sphere packing models would favor octahedral packing. $\mathrm{Ne}_{6} \mathrm{Cu}^{+}$had the largest computed dissociation energy in the size range $3 \leq n \leq 13$; its structure was a strongly distorted octahedron of $\mathrm{C}_{2 v}$ symmetry.

To summarize, local abundance maxima at $\mathrm{He}_{6} \mathrm{Cu}^{+}$ and $\mathrm{He}_{12} \mathrm{Cu}^{+}$have been tentatively assigned to octahedral and icosahedral structures; calculations are needed to confirm this conjecture. Existing theoretical reports of small $\mathrm{He}_{n} \mathrm{Cu}^{+}$and larger $\mathrm{Ne}_{n} \mathrm{Cu}^{+}$indicate that $\mathrm{He}_{n} \mathrm{Cu}^{+}$ cannot be modeled by simple pairwise additive potentials. We have made no attempt to provide structural models for $\mathrm{He}_{24} \mathrm{Cu}^{+}$and $\mathrm{He}_{2} \mathrm{Cu}_{2}{ }^{+}$which also seem to enjoy enhanced stability.

\section{Conclusion}

We have attempted to detect evidence for the production and release of $\mathrm{H}_{2}$ from cationic copper-water complexes in the gas phase. The reaction would have to proceed after (or upon) ionization because of the low temperature of the helium droplets in which the neutral precursors are grown. We failed to detect the telltale of $\mathrm{H}_{2}$ production, i.e. ions of the composition $\left(\mathrm{H}_{2} \mathrm{O}\right)_{n-2}(\mathrm{OH})_{2} \mathrm{Cu}_{m}{ }^{+}$or the isobaric $\left(\mathrm{H}_{2} \mathrm{O}\right)_{n-1} \mathrm{OCu}_{m}{ }^{+}$(or $\left(\mathrm{H}_{2} \mathrm{O}\right)_{n-2} \mathrm{O}_{2} \mathrm{Cu}_{m}{ }^{+}$which would indicate the production of $2 \mathrm{H}_{2}$ ). In future work we plan to use isotopically enriched copper; this would greatly reduce the number of isotopologues for ions containing several copper atoms, and increase the sensitivity for the detection of $\left(\mathrm{H}_{2} \mathrm{O}\right)_{n-x} \mathrm{O}_{x} \mathrm{Cu}_{m}{ }^{+}$.

We did detect ions that suggest highly size-dependent reactions, namely very intense signals for $\left(\mathrm{H}_{2} \mathrm{O}\right) \mathrm{OHCu}_{2}{ }^{+}$ and $\left(\mathrm{H}_{2} \mathrm{O}\right)_{2} \mathrm{OHCu}_{2}{ }^{+}$; the latter forms a maximum in the $\left(\mathrm{H}_{2} \mathrm{O}\right)_{n} \mathrm{OHCu}_{2}{ }^{+}$series and exceeds the abundance of $\left(\mathrm{H}_{2} \mathrm{O}\right)_{3} \mathrm{Cu}_{2}{ }^{+}$.

Another interesting observation is the large abundance of $\mathrm{He}_{6} \mathrm{Cu}^{+}, \mathrm{He}_{12} \mathrm{Cu}^{+}, \mathrm{He}_{24} \mathrm{Cu}^{+}$, and $\mathrm{He}_{2} \mathrm{Cu}_{2}{ }^{+}$. It is tempting to speculate that the apparently high stability of the first two of these ions correlates with octahedral and icosahedral arrangements of the solvent atoms. Theoretical work is needed to confirm these conjectures, and to provide a rational for the postulated enhanced stability of $\mathrm{He}_{24} \mathrm{Cu}^{+}$and $\mathrm{He}_{2} \mathrm{Cu}_{2}$.

This work was given financial support by the Austrian Science Fund (FWF) Wien (Project P26635) and the European Commission (ELEVATE, Horizon 2020 research and innovation program under grant agreement No. 692335). Open access funding provided by Austrian Science Fund (FWF).

\section{Author contribution statement}

P. Scheier conceived the project; S. Raggl, N. Gitzl, and P. Martini carried out the experimental work and data analysis; O. Echt prepared a draft of the manuscript; all authors discussed the results and commented on the manuscript.

Open Access This is an open access article distributed under the terms of the Creative Commons Attribution License (http://creativecommons.org/licenses/by/4.0), which permits unrestricted use, distribution, and reproduction in any medium, provided the original work is properly cited.

\section{References}

1. Z.X. Yang, L.G. Xie, D.W. Ma, G.T. Wang, J. Phys. Chem. C 115, 6730 (2011)

2. J. Xiong, X.D. Wu, Q.J. Xue, J. Colloid Interface Sci. 390 , $41(2013)$

3. N.K. Das, S. Ghosh, A. Priya, S. Datta, S. Mukherjee, J. Phys. Chem. C 119, 24657 (2015)

4. T. Kruk, K. Szczepanowicz, J. Stefanska, R.P. Socha, P. Warszynski, Colloids Surf. B-Biointerfaces 128, 17 (2015)

5. Z.K. He, J.W. Fu, B. Cheng, J.G. Yu, S.W. Cao, Appl. Catal. B-Environ. 205, 104 (2017)

6. Y.P. Liu et al., Adv. Mater. 29 (2017)

7. G. Hultquist, M.J. Graham, O. Kodra, S. Moisa, R. Liu, U. Bexell, J.L. Smialek, Corros. Sci. 95, 162 (2015)

8. A.J. Johansson, C. Lilja, T. Brinck, J. Chem. Phys. 135, 084709 (2011)

9. C.M. Lousada, A.J. Johansson, P.A. Korzhavyi, J. Phys. Chem. C 119, 14102 (2015)

10. K. Andersson, G. Ketteler, H. Bluhm, S. Yamamoto, H. Ogasawara, L.G.M. Pettersson, M. Salmeron, A. Nilsson, J. Am. Chem. Soc. 130, 2793 (2008)

11. P. Kappen, J.D. Grunwaldt, B.S. Hammershoi, L. Troger, B.S. Clausen, J. Catal. 198, 56 (2001)

12. M. Estrella et al., J. Phys. Chem. C 113, 14411 (2009)

13. S. Huseyinova, J. Blanco, F.G. Requejo, J.M. Ramallo-Lopez, M.C. Blanco, D. Buceta, M.A. Lopez-Quintela, J. Phys. Chem. C 120, 15902 (2016)

14. L. Chen et al., Phys. Chem. Chem. Phys. 12, 9845 (2010)

15. J.H. Stenlid, A.J. Johansson, T. Brinck, Phys. Chem. Chem. Phys. 16, 2452 (2014)

16. J.H. Stenlid, A.J. Johansson, L. Kloo, T. Brinck, J. Phys. Chem. C 120, 1977 (2016) 
17. M.L. Jiang, Q. Zeng, T.T. Zhang, M.L. Yang, K.A. Jackson, J. Chem. Phys. 136, 104501 (2012)

18. P.M. Holland, A.W. Castleman, J. Chem. Phys. 76, 4195 (1982)

19. T.F. Magnera, D.E. David, D. Stulik, R.G. Orth, H.T. Jonkman, J. Michl, J. Am. Chem. Soc. 111, 5036 (1989)

20. N.F. Dalleska, K. Honma, L.S. Sunderlin, P.B. Armentrout, J. Am. Chem. Soc. 116, 3519 (1994)

21. P.J.E. Boussard, P.E.M. Siegbahn, M. Svensson, Chem. Phys. Lett. 231, 337 (1994)

22. A.M. El-Nahas, N. Tajima, K. Hirao, J. Mol. Struct. THEOCHEM 469, 201 (1999)

23. D. Feller, E.D. Glendening, W.A. de Jong, J. Chem. Phys. 110, 1475 (1999)

24. H.M. Lee, S.K. Min, E.C. Lee, J.H. Min, S. Odde, K.S. Kim, J. Chem. Phys. 122, 064314 (2005)

25. J.D. Herr, R.P. Steele, J. Phys. Chem. A 120, 10252 (2016)

26. T. Iino, K. Ohashi, Y. Mune, Y. Inokuchi, K. Judai, N. Nishi, H. Sekiya, Chem. Phys. Lett. 427, 24 (2006)

27. T. Iino, K. Ohashi, K. Inoue, K. Judai, N. Nishi, H. Sekiya, J. Chem. Phys. 126, 194302 (2007)

28. P.D. Carnegie, A.B. McCoy, M.A. Duncan, J. Phys. Chem. A 113, 4849 (2009)

29. B.M. Marsh, J. Zhou, E. Garand, J. Phys. Chem. A 118, 2063 (2014)

30. B.M. Marsh, J. Zhou, E. Garand, Phys. Chem. Chem. Phys. 17, 25786 (2015)

31. A.F. Sweeney, J.T. O'Brien, E.R. Williams, P.B. Armentrout, Int. J. Mass Spectrom. 378, 270 (2015)

32. A.F. Sweeney, P.B. Armentrout, J. Phys. Chem. A 118, 10210 (2014)

33. V.A. Mikhailov, P.E. Barran, A.J. Stace, Phys. Chem. Chem. Phys. 1, 3461 (1999)

34. G.E. Froudakis, M. Muhlhauser, S.C. Farantos, A. Sfounis, M. Velegrakis, Chem. Phys. 280, 43 (2002)
35. L.F. Gomez, E. Loginov, R. Sliter, A.F. Vilesov, J. Chem. Phys. 135, 154201 (2011)

36. H. Schöbel, P. Bartl, C. Leidlmair, S. Denifl, O. Echt, T.D. Märk, P. Scheier, Eur. Phys. J. D 63, 209 (2011)

37. S. Ralser, J. Postler, M. Harnisch, A.M. Ellis, P. Scheier, Int. J. Mass Spectrom. 379, 194 (2015)

38. A. Mauracher, M. Daxner, J. Postler, S.E. Huber, S. Denifl, P. Scheier, J.P. Toennies, J. Phys. Chem. Lett. 5, $2444(2014)$

39. O. Echt, D. Kreisle, M. Knapp, E. Recknagel, Chem. Phys. Lett. 108, 401 (1984)

40. S. Denifl et al., J. Chem. Phys. 132, 234307 (2010)

41. S. Krückeberg, L. Schweikhard, J. Ziegler, G. Dietrich, K. Lutzenkirchen, C. Walther, J. Chem. Phys. 114, 2955 (2001)

42. C.E. Klots et al., Z. Phys. D 21, 335 (1991)

43. K. Hansen, U. Näher, Phys. Rev. A 60, 1240 (1999)

44. L. An der Lan, P. Bartl, C. Leidlmair, R. Jochum, S. Denifl, O. Echt, P. Scheier, Chem. Eur. J. 18, 4411 (2012)

45. P. Bartl, C. Leidlmair, S. Denifl, P. Scheier, O. Echt, J. Phys. Chem. A 118, 8050 (2014)

46. T. Döppner, T. Diederich, S. Gode, A. Przystawik, J. Tiggesbäumker, K.H. Meiwes-Broer, J. Chem. Phys. 126, 244513 (2007)

47. M. Goulart et al., Phys. Chem. Chem. Phys. 20, 9554 (2018)

48. F. Tramonto, P. Salvestrini, M. Nava, D.E. Galli, J. Low Temp. Phys. 180, 29 (2015)

49. D. Prekas, C. Lüder, M. Velegrakis, J. Chem. Phys. 108, 4450 (1998)

50. A. Yousef, S. Shrestha, L.A. Viehland, E.P.F. Lee, B.R. Gray, V.L. Ayles, T.G. Wright, W.H. Breckenridge, J. Chem. Phys. 127, 154309 (2007)

51. X.F. Tong, C.L. Yang, M.S. Wang, X.G. Ma, D.H. Wang, J. Chem. Phys. 134, 024306 (2011)

52. X.Y. Li, X.Y. Cheng, X. Cao, Struct. Chem. 23, 1831 (2012) 